\title{
Microdissection Testicular Sperm Extraction: Preoperative Patient Optimization, Surgical Technique, and Tissue Processing
}

\author{
Ryan K. Flannigan1, Peter N. Schlegel2 \\ ${ }^{1}$ British Colombia University Faculty of Medicine, Department of Urologic Sciences, Vancouver, British Columbia, Canada, ABD \\ 2 Weill Cornell Medicine, Department of Urology, New York, ABD
}

Fertil Steril. 2019 Mar;111:420-426. doi: 10.1016/j.fertnstert.2019.01.003.

\section{EDITORIAL COMMENT}

The optimal approach for finding spermatozoa in testicular tissue in patients with nonobstructive azoospermia is microdissection Testicular Sperm Extraction (mTESE) operation. In this review article, the authors summarized and evaluated the literature regarding the patient optimization before mTESE, mTESE technique and post-testicular tissue processing. There are limited data and no controlled arm studies to evaluate the efficacy of adjuvant hormone therapy to support increased sperm retrieval. In order to show the effect of varicocele repair in testicular sperm recovery, we need further evidence-based studies with controlled groups to motivate us to pursue varicocele operation in men with nonobstructive azoospermia. For identifying sperm in testicular tissue, experience of the embryologist in tissue preparation using methods, such as mechanical mincing technique, and using erythrocyte-lysing buffer or collagenase is very important.

Emre BAKIRCIOĞLU, MD

${ }^{\circ}$ Copyright 2019 by the Association of Urological Surgery / Journal of Urological Surgery published by Galenos Publishing House. 